\title{
Interaction of curcumin nanoformulations with human plasma proteins and erythrocytes
}

This article was published in the following Dove Press journal:

International Journal of Nanomedicine

7 November 2011

Number of times this article has been viewed

\section{Murali Mohan Yallapu' \\ Mara C Ebeling' \\ Neeraj Chauhan ${ }^{1,3}$ \\ Meena Jaggi ${ }^{1-3}$ \\ Subhash C Chauhan ${ }^{1-3}$}

'Cancer Biology Research Center, Sanford Research, ${ }^{2}$ Department of Obstetrics and Gynecology, ${ }^{3}$ Basic Biomedical Science Division, Sanford School of Medicine, University of South Dakota, Sioux Falls, SD

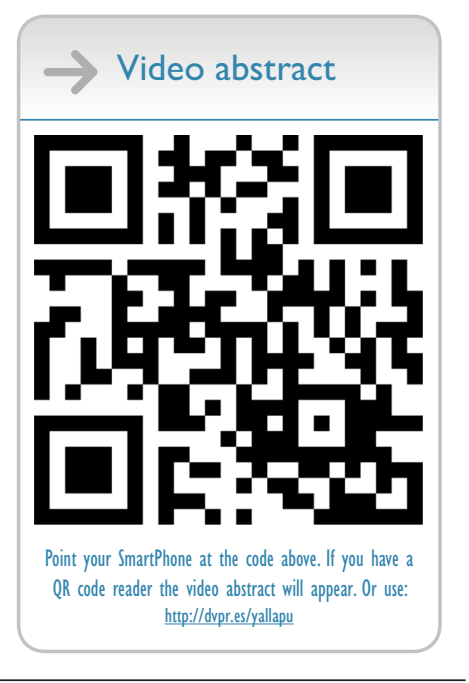

Correspondence: Subhash C Chauhan Cancer Biology Research Center, Sanford Research/University of South Dakota, 230I E 60th Street North, Sioux Falls, SD 57104-0589, USA

$\mathrm{Tel}+\mathrm{I} 6053126106$

Fax + I $605312607 \mid$

Email subhash.chauhan@sanfordhealth.org
Background: Recent studies report curcumin nanoformulation(s) based on polylactic- $\mathrm{co}$-glycolic acid (PLGA), $\beta$-cyclodextrin, cellulose, nanogel, and dendrimers to have anticancer potential. However, no comparative data are currently available for the interaction of curcumin nanoformulations with blood proteins and erythrocytes. The objective of this study was to examine the interaction of curcumin nanoformulations with cancer cells, serum proteins, and human red blood cells, and to assess their potential application for in vivo preclinical and clinical studies.

Methods: The cellular uptake of curcumin nanoformulations was assessed by measuring curcumin levels in cancer cells using ultraviolet-visible spectrophotometry. Protein interaction studies were conducted using particle size analysis, zeta potential, and Western blot techniques. Curcumin nanoformulations were incubated with human red blood cells to evaluate their acute toxicity and hemocompatibility.

Results: Cellular uptake of curcumin nanoformulations by cancer cells demonstrated preferential uptake versus free curcumin. Particle sizes and zeta potentials of curucumin nanoformulations were varied after human serum albumin adsorption. A remarkable capacity of the dendrimer curcumin nanoformulation to bind to plasma protein was observed, while the other formulations showed minimal binding capacity. Dendrimer curcumin nanoformulations also showed higher toxicity to red blood cells compared with the other curcumin nanoformulations.

Conclusion: PLGA and nanogel curcumin nanoformulations appear to be very compatible with erythrocytes and have low serum protein binding characteristics, which suggests that they may be suitable for application in the treatment of malignancy. These findings advance our understanding of the characteristics of curcumin nanoformulations, a necessary component in harnessing and implementing improved in vivo effects of curcumin.

Keywords: nanoparticle, curcumin, chemotherapy, cellular uptake, protein binding, hemocompatibility

\section{Introduction}

Curcumin (structure shown in Figure 1A) is a natural diphenolic compound extracted from the herb Curcuma longa, and is widely used in traditional Indian and Chinese medicine. Curcumin has numerous biological and pharmacological activities, with no major side effects, and is currently being used in several clinical trials for treating several disorders, including Alzheimer's disease, hypercholesterolemia, atherosclerosis, psoriasis, Crohn's disease, neurological disorders, and cancer. ${ }^{1,2}$ Recent studies establish that curcumin can be translated into a therapeutic molecule to treat a variety of cancers. ${ }^{3,4}$ In addition, studies have demonstrated that curcumin is an efficient molecule for overcoming multidrug resistance phenomena as well as inducing sensitization of tumor cells for chemotherapy and radiation. ${ }^{5-10}$ Unfortunately, the strong potential 
A<smiles>COc1cc(/C=C/C(=O)/C=C(O)/C=C/c2ccc(O)c(OC)c2)ccc1O</smiles>

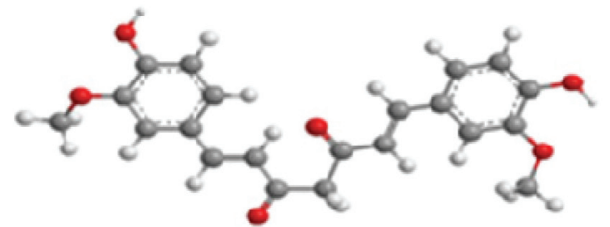

B

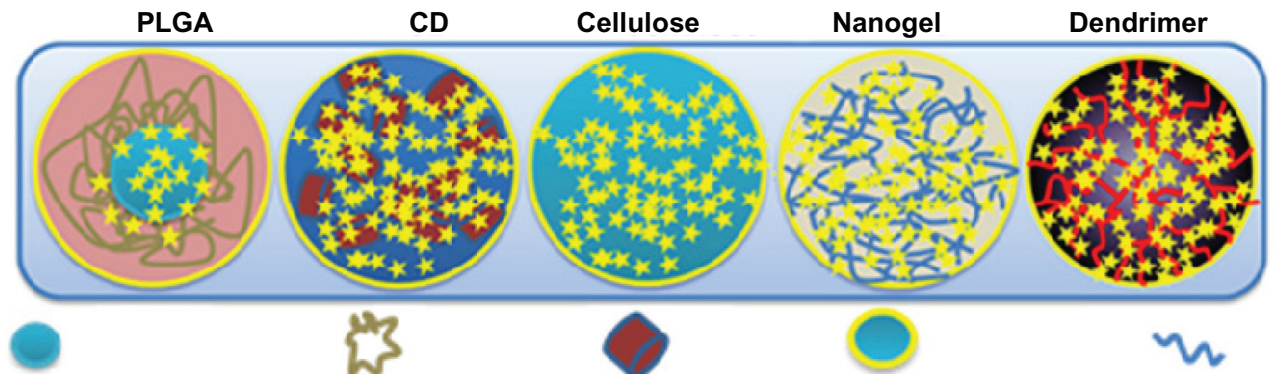

PLGA polymer core

PVA/PLL polymer chain cyclic structure matrix chain in nanogel
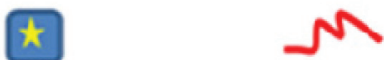

Curcumin

\section{Poly (amidoamine) chain in dendrimer}

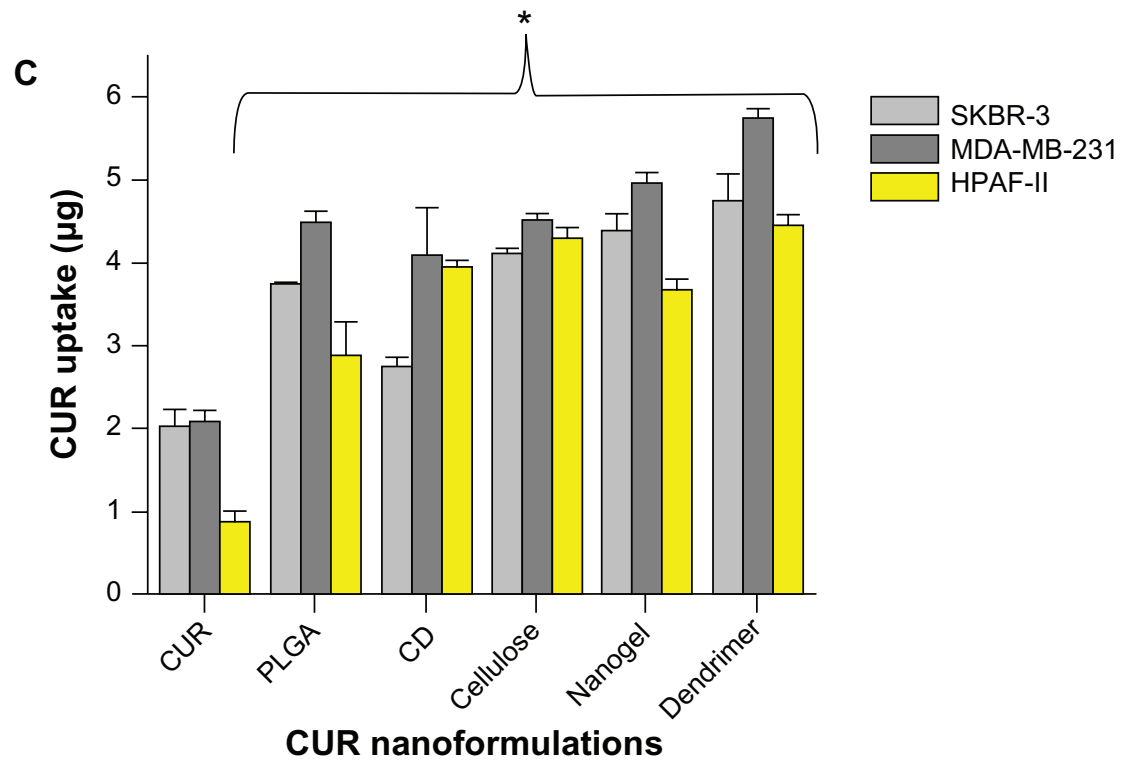

Figure I Structural variations of the curcumin nanoformulations and their uptake in cancer cells. (A) Chemical structure of curcumin. (B) Different types of curcumin nanoformulations and their structures based on chemical composition. Structures do not represent exact size or orientation, and the solid background is intended to distinguish the different formulations. Entire polymer chains, drugs (curcumin), and other structures are defined in the figure itself. (C) Cellular uptake of curcumin nanoformulations in SKBR-3, MDA-MB-23I, and HPAF-II cancer cells. Cancer cells were treated with curcumin $20 \mu \mathrm{g}$ or curcumin nanoformulations (20 $\mu \mathrm{g}$ equivalent to curcumin) for 6 hours. Uptake was determined by recording absorption of acetone cell lysates at $\lambda \max 450 \mathrm{~nm}$ using UV-vis spectrophotometer.

Notes: Data are reported as the mean of three repeats for each uptake (mean \pm standard error of the mean deviation; $* P<0.05$, curcumin nanoformulations versus free curcumin).

Abbreviations: CD, $\beta$-cyclodextrin; CUR, curcumin; PLGA, polylactic-co-glycolic acid; PVA, polyvinyl alcohol; PLL, poly-L-lysine.

of curcumin to improve the effectiveness of cancer treatment is hindered by its poor bioavailability, attributable to its poor aqueous solubility, degradation, and high rate of metabolism. ${ }^{11-13}$

Because of its hydrophobic nature and poor bioavailability, the clinical development of curcumin as a "medicine" is dependent upon developing a nanocarrier for efficient transport in the body. ${ }^{12,14,15}$ Recently, several curcumin nanoformulations, such as polymer nanoparticles, selfassemblies, nanocrystal dispersions, nanoemulsions, lipid nanoparticles, and protein-based drug delivery systems, have shown improved solubility, stability, and bioavailability of the curcumin molecule. ${ }^{14-20}$ Moreover, curcumin nanoformulations have demonstrated improved cellular uptake in cancer models that increases the chance of a positive therapeutic outcome. Curcumin nanoformulations 
have also exhibited superior in vitro anticancer responses compared with free curcumin due to sustained release of the active compound and the enhanced permeation and retention effects of nanoformulations. ${ }^{16,19,21,22}$ Several of these nanoformulations have been successful in raising the area under the concentration-time curve, half-life, and mean residence time of curcumin in serum and in various organs. ${ }^{16,23-25} \mathrm{In}$ our previous study, we describe a comparative evaluation of $\beta$-cyclodextrin, hydroxyl propyl methyl cellulose (cellulose), polylactic-co-glycolic acid (PLGA) and dendrimer curcumin nanoformulations with free curcumin using cytotoxicity, cellular uptake, and apoptosis studies in cancer cells and suggests a close relationship with the therapeutic efficacy of the formulation. ${ }^{26}$ However, there is no tool to evaluate the behavior of curcumin nanoformulations in vivo. Similarly, while a number of curcumin nanoformulations have been reported in the literature, so far there has been no comparative study to evaluate which formulation(s) is more efficient for in vivo cancer therapeutics.

Preclinical properties of nanoformulations depend upon avoiding rapid clearance from the systemic circulation by the cells of the immune system. ${ }^{27-29}$ Usually, the in vivo fates of nanoformulations follow many potential routes before reaching their actual target(s)..$^{30-32}$ Therefore, the in vivo outcome of nanoformulations depends on the biological fluid interactions with particle surfaces where particles may aggregate or stabilize, or be subjected to clearance, uptake, and trafficking processes. ${ }^{33-35}$ Conventional nanoparticle formulations readily interact with plasma proteins, opsonize, and are taken from the blood circulation by phagocytes. Modification of the surface properties of nanoformulations remains a key feature that can enhance their half-life, which is likely to be predictive of therapeutic outcome. Further, hemocompatibility of nanoformulations is an initial check point in understanding their utility in vivo. Therefore, the aim of this study was to examine the interaction of curcumin nanoformulations with plasma proteins and red blood cells and as a result, predict the implications of their biological characteristics for in vivo application.

\section{Materials and methods}

Curcumin ( $\geq 95 \%$ purity), $\beta$-cyclodextrin, cellulose (molecular weight 10,000 , methoxy $1.8-2.0$ and propylene oxide $0.2-0.3$, viscosity $2 \mathrm{wt} \%$ in water, $5 \mathrm{cps}$ ), polyvinyl alcohol (molecular weight 30,000-70,000), poly-L-lysine (molecular weight 30,000-70,000), $N$-isopropyl acrylamide (NIPAM), polyamidoamine dendrimer generation 4 ( $10 \mathrm{wt} \%$ solution $)$, sodium dodecyl sulfate, fibrinogen, immunoglobulin G, transferrin, human serum albumin (HSA) and acetone ( $\geq 99.5$, American Chemical Society reagent grade) were purchased from Sigma Chemical Co (St Louis, MO). PLGA, 50:50 lactide-glycolide ratio, inherent viscosity $1.32 \mathrm{dL} / \mathrm{g}$ at $30^{\circ} \mathrm{C}$ ) was purchased from Birmingham Polymers (Pelham, AL). All chemicals were used as received without further purification. Ultrapure water was produced by purification with an Ultrapure $^{\circledR}$ water system (Elga, Woodridge, IL). Curcumin nanoformulations (Figure 1B) were obtained following our previous protocols using PLGA, $\beta$-cyclodextrin, cellulose, nanogel (polyNIPAM), and dendrimer through self-assembly/ complexation/redox free radical solution polymerization or encapsulation techniques..$^{21,22,26,36}$ For consistency, all curcumin nanoformulations were processed with $20 \mathrm{wt} \%$ curcumin loading. A schematic representation of curcumin nanoformulations are provided in Figure 1B.

\section{In vitro cellular uptake}

In vitro cellular uptake studies were performed as described in our previous reports. ${ }^{21,22}$ MDA-MB-231, SKBR-3 (breast), and HPAF-II (pancreatic) cancer cells $\left(1 \times 10^{5}\right)$ in Dulbecco's modified Eagle's medium or F12 medium were incubated in either $20 \mu \mathrm{g}$ of free curcumin (dissolved in dimethylsulfoxide) or an equivalent amount of curcumin nanoparticles. After 6 hours of incubation, the cells were washed with phosphate-buffered solution (10 mM, pH 7.4), trypsinized, and centrifuged at $1000 \mathrm{rpm}$. The cell pellet containing curcumin in cancer cells was resuspended in $1 \mathrm{~mL}$ of acetone and sonicated for 5 minutes. The lysates were centrifuged at 12,000 rpm for 15 minutes and the curcumin levels were recorded for the supernatant curcumin solution..$^{21}$ A standard plot of curcumin in acetone $(1-10 \mu \mathrm{g})$ was prepared identically to calculate curcumin uptake by the cells.

\section{Protein adsorption}

\section{Particle size, shape, and zeta potential}

The particle size, shape, and zeta potential of nanoparticles can vary after serum protein adsorption/interaction. To evaluate this phenomenon, curcumin nanoformulations $(1 \mathrm{mg} / \mathrm{mL})$ were dispersed in $100 \mu \mathrm{g}$ HSA for 2 hours at $25^{\circ} \mathrm{C}$. The nanoformulations were centrifuged at $12,000 \mathrm{rpm}$ for 15 minutes to obtain HSA-bound nanoparticles. The particle size and zeta potential of HSA-bound curcumin nanoformulations were measured using a Delsa ${ }^{\mathrm{TM}}$ Nano $\mathrm{C}$ particle size analyzer (Beckman Coulter, Miami, FL). Particle size and distribution was measured for 3 minutes, and the zeta potential was measured for 90 runs (9 minutes). The surface morphology of curcumin formulations and HSA-bound curcumin 
nanoformulations was observed under a JEOL-1210 transmission electron microscope (JEOL, Tokyo, Japan) operating at $80 \mathrm{kV}$. The nanoformulation samples were stained with uranyl acetate solution to accentuate fine structures under transmission electron microscopy.

\section{Western blot}

Curcumin nanoformulations $(20 \mu \mathrm{M})$ were incubated in $100 \mu \mathrm{g}$ of various plasma protein solutions at $37^{\circ} \mathrm{C}$. During incubation, adsorption of proteins occurred on the nanoparticle surfaces. Following 2 hours of incubation, the samples were centrifuged at $12,000 \mathrm{rpm}$ for 15 minutes to obtain pellets of protein-adsorbed curcumin nanoparticles. The adsorbed proteins were removed by adding an electrophoresis sample buffer (Santa Cruz Biotechnology, Santa Cruz, $\mathrm{CA}$ ) and heating to $95^{\circ} \mathrm{C}$ for 5 minutes. These protein samples were loaded in 4\%-20\% polyacrylamide gel and then underwent sodium dodecyl sulfate-polyacrylamide gel electrophoresis at $150 \mathrm{~V}$ for 60 minutes. The gels were placed in $100 \mathrm{~mL}$ ultrapure water and microwaved (Emerson ${ }^{\circledR}$ microwave oven, MW8777 W, $700 \mathrm{~W}$ ) on high for 3 minutes and allowed to cool down for 5 minutes. After the water was discarded, $20 \mathrm{~mL}$ of SimplyBlue ${ }^{\mathrm{TM}}$ SafeStain solution (Coomassie ${ }^{\circledR}$ G-250 stain, Invitrogen, Carlsbad, CA) was added and the gel was microwaved on high for 45 seconds. The gel was allowed to cool down, washed with ultrapure water and incubated in $20 \mathrm{~mL}$ of $20 \%$ sodium chloride solution for 5 minutes. The gels were scanned using a BioRad Gel Doc (BioRad, Hercules, CA) and the intensity quantification of bands was acquired using AlphaEase Fc software. ${ }^{10}$

\section{Flow cytometry}

To determine the adhesion properties of curcumin nanoformulations in human red blood cells, a flow cytometric assay was employed. For this study, $100 \mu \mathrm{L}$ of healthy male human blood (Biological Specialty Corporation, Colmar, PA) was incubated with 10-40 $\mu \mathrm{M}$ curcumin nanoformulations for 2 hours in $1 \mathrm{~mL}$ of RPMI medium at $37^{\circ} \mathrm{C}$. During incubation, the curcumin nanoformulations readily established interaction with plasma proteins while the free curcumin nanoparticles bound with red blood cells.

After incubation, the entire solution was filtered through a polystyrene round-bottom tube with cell-strainer cap and injected into an Acuri C6 Flow Cytometer (AccuriтM Cytometers Inc, Ann Arbor, MI) to determine the fluorescence levels of curcumin nanoformulations attached to red blood cells in flow channel 1 absorbance (FL1A,
488 excitation, blue laser, $530 \pm 15 \mathrm{~nm}$, fluorescein isothiocyanate/green fluorescent protein). Red blood cells were first gated using side and forward scatter in the Accuri software and nanocurcumin particles bound to red blood cells in this range only were analyzed by flow cytometry. Because unbound nanoparticles were way below the range, they did not interfere with the data.

\section{Hemolysis test}

Hemolysis causes damage to red blood cells via the release of iron-containing protein hemoglobin into plasma. To evaluate curcumin nanoformulations for human use, formulations must first be checked for hemolytic compatibility. In this study, $8 \mathrm{~mL}$ of whole blood from a healthy male was centrifuged at $2000 \mathrm{rpm}$ for 10 minutes to obtain red blood cells, which were then resuspended in $8 \mathrm{~mL}$ RPMI 1640 growth media. Different concentrations of curcumin nanoformulations $(0-200 \mu \mathrm{M})$ were incubated at $37^{\circ} \mathrm{C}$ with $100 \mu \mathrm{L}$ red blood cells in Eppendorf tubes. After 2 hours of incubation at $37^{\circ} \mathrm{C}$, the extent of hemolysis caused by curcumin nanoformulations was observed macroscopically, the tubes were centrifuged, and the supernatant fluid was measured for optical density at $\lambda \max 570 \mathrm{~nm}$ using ultraviolet-visible spectrophotometry (BioMate 3 spectrophotometer, Thermo Electron Corporation, Waltham, MA). Phosphate-buffered solution and sodium dodecyl sulfate were used as the negative and positive controls, respectively. To observe the visual effect of red blood cell membrane damage, the red blood cell pellets were redispersed in phosphate-buffered solution after treatment, and a drop of solution was placed on a glass slide for imaging using an Olympus BX 41 phase contrast microscope (Olympus, Center Valley, PA). A transmission electron microscopy study was performed according to our previously reported method to identify further nanoparticle association with the red blood cells. ${ }^{21}$

\section{Statistical analysis}

The data were processed using Microsoft Excel 2007 software and presented as the mean \pm standard error of the mean. Statistical analyses were performed for the overall comparison between groups using analysis of variance models. If the analysis of variance model F-test was significant at the 0.05 level, the difference between groups was examined using a pairwise $t$-test and each group was compared with the control. The analysis was performed using SAS 9.2 (SAS Institute, Inc, Cary, NC). All graphs were plotted using Origin 6.1 software. 


\section{Results and discussion}

Many reports confirm that nanoparticles with a size of less than $200 \mathrm{~nm}$ can be taken up by cancer cells through endocytosis or diffusion. ${ }^{37-39}$ In addition to particle size, the type and surface characteristics of nanoformulations contribute to the regulation of uptake. ${ }^{40-42}$ Some nanoformulations are toxic due to the surfactants used in their preparation. Therefore, in this study we explored the feasibility of five different curcumin nanoformulations for cancer therapy based on cancer cell uptake, as well as their interaction with human plasma proteins and red blood cells.

\section{Cellular uptake}

First, all five curcumin nanoparticle formulations were studied for uptake into SKBR-3, MDA-MB-231 (breast), and HPAF-II (pancreatic) cancer cells to evaluate their feasibility as drug (curcumin) delivery vehicles. This uptake study will be useful to identify which curcumin nanoformulations are efficient compared with free curcumin. Uptake was achieved by incubating the cancer cells with $20 \mu \mathrm{g}$ of curcumin or $20 \mu \mathrm{g}$ equivalent curcumin nanoparticles for 6 hours. Curcumin uptake was determined by the absorbance measurement of acetone-extracted cell lysates. Preferential uptake of curcumin was observed in all three cancer cells by the curcumin nanoformulations in comparison with free curcumin (Figure 1C). This enhanced uptake behavior of various curcumin nanoformulations has been observed previously in many cancer cells. ${ }^{16,21,22,43-45}$ Curcumin uptake in cancer cells, in descending order, was found to be MDA-MB-231 > SKBR-3 > HPAF-II. Overall, the dendrimer curcumin formulation showed noticeably higher uptake by cancer cells than the PLGA, $\beta$-cyclodextrin, cellulose, and nanogel curcumin formulations. This significantly higher uptake could be due to the positive zeta potential or higher penetration capacity via functional amino groups on the dendrimer. These results suggest that nanoparticle-mediated delivery of curcumin is more efficient and better able to reach cancer cells than free curcumin, and may effectively improve therapeutics. Although all five curcumin nanoformulations showed enhanced uptake, their in vivo properties may be different, depending on several factors, including stability of the curcumin nanoformulations in the presence of blood proteins and interaction with erythrocytes. Therefore, we investigated interaction of blood proteins and erythrocytes for all five curcumin formulations.

\section{Association of curcumin nanoparticles with HSA}

Newly developed drug nanoformulations may have a direct interaction with tissues and cells after administration to animals and humans. ${ }^{46}$ The ability of nanoformulations to achieve a higher therapeutic value relies on their biocompatibility and lower serum protein binding capacity which, in turn, is important for industrialization. In general, serum proteins readily bind onto the surfaces of various nanoparticles within one hour. ${ }^{47,48}$ Proteins adsorb on the surfaces of nanoparticles quickly and their characteristics may change before reaching the intended target(s). The degree of protein interaction may depend on particle size, surface stabilization, functional or chemical groups on the surface, and composition of the particles. ${ }^{48-52}$ Therefore, we first addressed how the curcumin nanoparticles surface is adsorbed by HSA. We chose HSA because it is the most abundant protein in human plasma (3.4-5.4 g/dL).

Different curcumin nanoparticles have variable particle sizes and morphology (Figure 2A, top panel). PLGA, $\beta$-cyclodextrin, cellulose, nanogel, and dendrimer curcumin nanoformulations had particle sizes of about 52, 41, 36, 48 , and $42 \mathrm{~nm}$, respectively. After incubation with HSA, most of the nanoparticles had a similar particle size, but their morphology was distinctive, ie, they were either coated with HSA corona or showed a change in their aggregation behavior (Figure 2A, lower panel). This variation in the morphology of nanoparticles is similar to that caused by the formation of soft corona or loosely bound proteins on metal or polymer nanoparticle surfaces..$^{50,53,54}$ High accumulation of dark spots in the $\beta$-cyclodextrin and cellulose curcumin nanoformulations after HSA incubation is related to the stain (uranyl acetate, Figure 2A, red arrows) used to assist detection under transmission electron microscopy, not to actual nanoparticle aggregation. This may be because a higher rate of adsorption of metal ions to $\beta$-cyclodextrin and/or cellulose exists through an inclusion complex or ionic bonding. This behavior can be seen in $\beta$-cyclodextrin formulation before and after incubation with HSA (red arrows), but not in the cellulose formulation before incubation with HSA. A change in the overall particle morphology or structure after incubation with HSA may occur, and thus more dark staining is present in the case of the cellulose nanoformulation. In the case of the dendrimer curcumin nanoformulation, an aligned network was seen throughout the sample due to the HSA layers (Figure 2A, blue arrows).

Since most of the HSA protein adsorption is loosely coated to all curcumin nanoparticle surfaces, their overall particle size aggregation decreased (Figure 2B). This indicates that the adsorbed HSA helps to reduce particle-particle interaction but does not change in the individual particle 


\section{CUR nanoformulations}
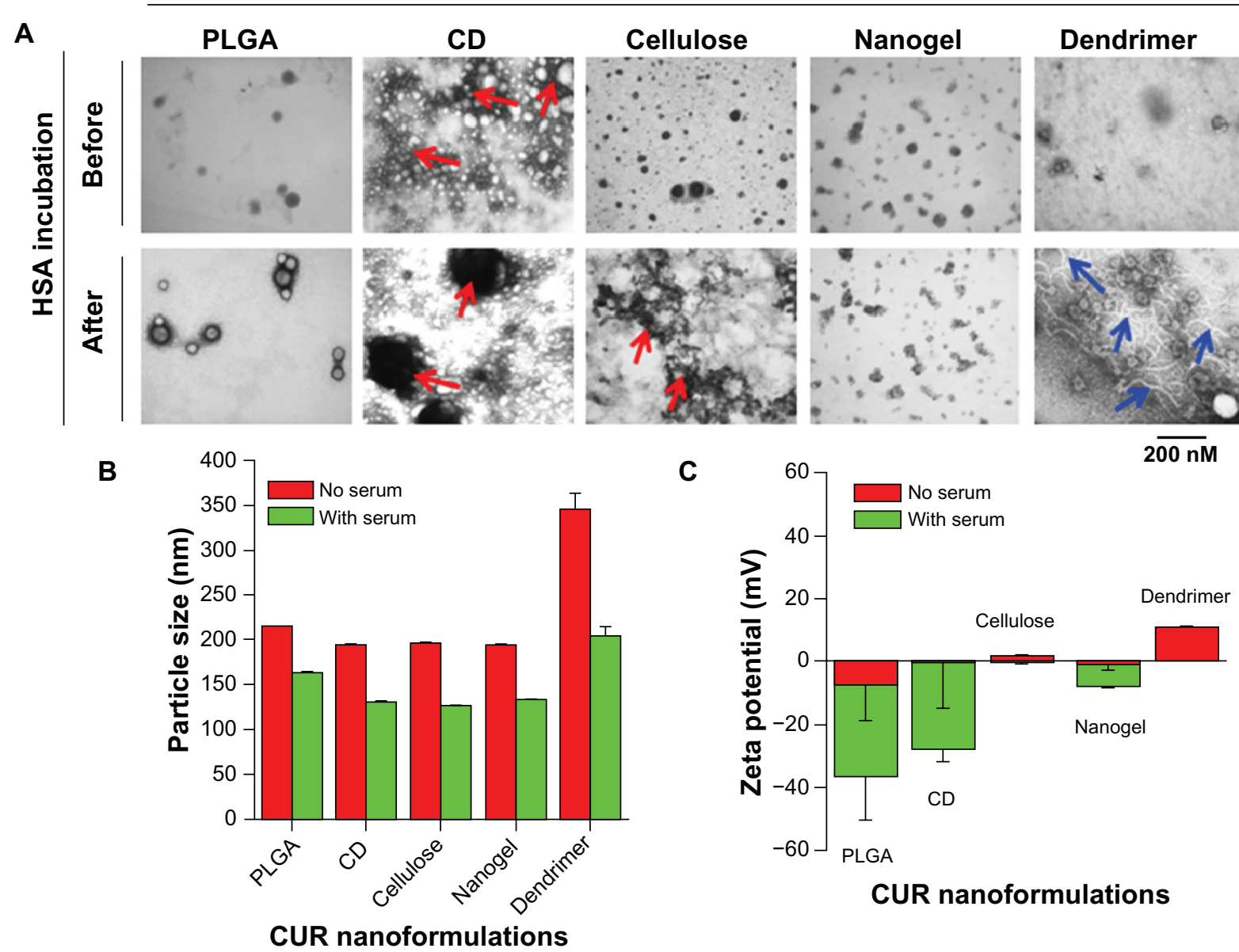

CUR nanoformulations

Figure 2 Human serum albumin binding alters the physicochemical properties of the curcumin nanoformulations, ie, PLGA, $\beta$-cyclodextrin, cellulose, nanogel, and dendrimecurcumin nanoparticles. (A) Transmission electron microscopic images of the curcumin nanoformulations (I mg/mL) before and after incubation with human serum albumin $100 \mu \mathrm{g}$. Incubation with human serum albumin was performed for 2 hours, after which the nanoparticles were deposited on transmission electron microscopy grids, stained with uranyl acetate, and imaged under transmission electron microscopy. Red arrows represent uranyl acetate over stain. Blue arrows indicate aliened HSA networks. (B-C) Change in particle size and zeta potential of curcumin nanoformulations before and after incubation with human serum albumin. Particle size was measured for 3 minutes and the zeta potential was measured for 90 runs ( 9 minutes).

Note: Data are reported as the mean \pm standard error of the mean for three repeats for each incubation.

Abbreviations: CD, $\beta$-cyclodextrin; CUR, curcumin; PLGA, polylactic-co-glycolic acid; HSA, human serum albumin.

grain size, as seen in the transmission electron microscopy study. A similar phenomenon was observed when nanoparticles were incubated with HSA, bovine serum albumin, or Tween 80 dispersions. ${ }^{53}$ However, we observed little change in the zeta potential of the curcumin nanoformulations after adsorption of HSA (Figure $2 \mathrm{C}$ ). The zeta potential values for the curcumin PLGA, $\beta$-cyclodextrin, and nanogel formulations were $-7.71,-0.41$, and $-1.46 \mathrm{mV}$, and the values for their HSA complexes further decreased to $-28.86,-27.63$, and $-7.28 \mathrm{mV}$, respectively. HSA-adsorbed molecules carry a net negative charge in aqueous solution, resulting in a lowered negative zeta potential. ${ }^{55}$ No significant change was observed in the zeta potential values of the cellulose and dendrimer curcumin nanoformulations after HSA complexation. This could be possible because a HSA corona was not formed, HSA was loosely bound on the surface of the nanoparticles, or because HSA polymer chains were dispersed throughout the nanoformulations.

\section{Interaction of curcumin nanoparticles with human serum proteins}

Chemotherapeutic drug nanoformulations intended for human applications need to be evaluated for their impact on the immune system. ${ }^{56-58}$ Some nanoparticles can escape the phagocytosis process but may have a tendency to bind to serum proteins which disturb native immunity. To avoid this problem, selection of nanoformulations must be based on minimal interaction with serum proteins. Low protein-binding nanoformulations may carry and deliver drug molecules to target site(s) for an extended period. On the other hand, higher protein binding may lead to aggregation of nanoformulations over time, that allows elimination from the body. In this study, 
we evaluated the adsorption of protein onto curcumin nanoparticles, which varies according to the type of plasma protein (Figure 3A). Fibrinogen and immunoglobulin $\mathrm{G}$ adsorption is very low, while transferrin and HSA adsorption is very high. The decreasing degree of protein adsorption to nanoparticles is $\mathrm{HSA}>$ transferrin $>$ immunoglobulin $\mathrm{G}>$ fibrinogen. However, it is evident that dendrimer curcumin nanoparticles adsorbed more proteins compared with other types of curcumin nanoparticles. This suggests a higher degree of association/interaction of plasma proteins with the dendrimer curcumin nanoformulation which may not be appropriate for in vivo therapeutics. Densitometry quantification revealed that the order of adsorption of proteins to the different curcumin nanoformulations was dendrimer $>\beta$-cyclodextrin $>$ cellulose $>$ nanogel $>$ PLGA (Figure 3B). A 3.0-3.5-fold increase in protein adsorption was found with dendrimer curcumin nanoparticles compared with PLGA curcumin nanoparticles. A similar pattern of binding was observed for all curcumin nanoformulations incubated with bovine serum albumin (data not shown).

Chambers and Mitragotri reported that nanoparticles attached to the surface of red blood cells can dramatically

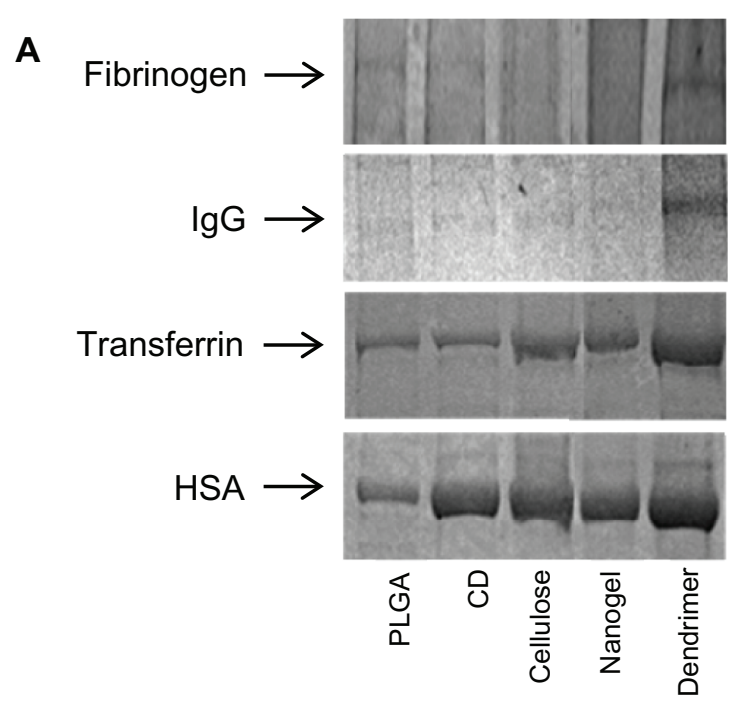

B

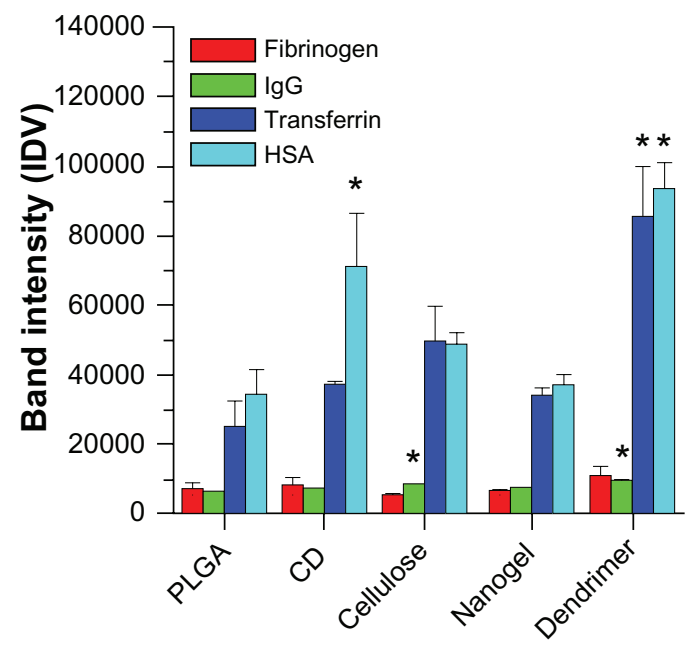

CUR nanoformulations

\section{CUR nanoformulations}

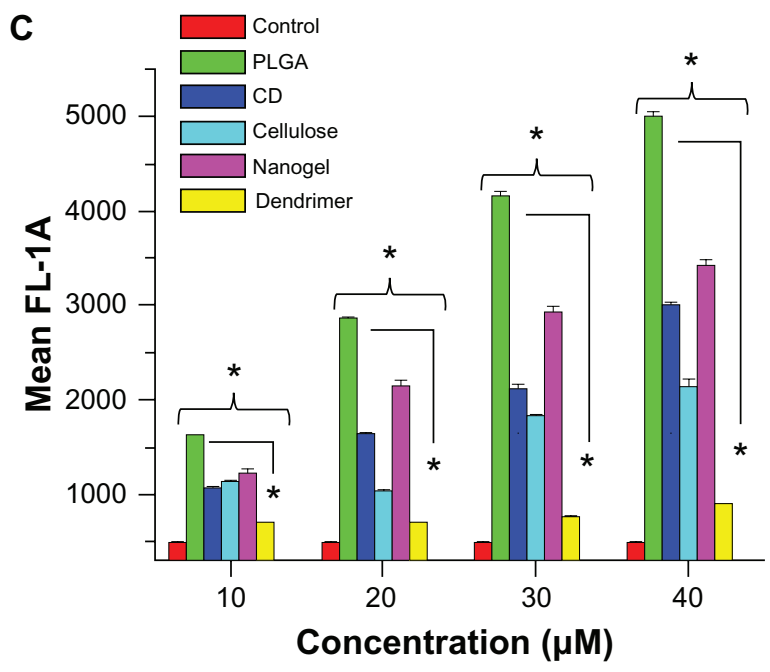

Figure 3 Human serum proteins binding to curcumin nanoformulations (PLGA, $\beta$-cyclodextrin, cellulose, nanogel, and dendrimer). (A) Sodium dodecyl sulfate-polyacrylamide gel electrophoresis of curcumin nanoformulations ( $20 \mu \mathrm{M})$ incubated in $100 \mu \mathrm{g}$ human plasma proteins (fibrinogen, immunoglobulin $\mathrm{G}$, transferrin, and serum albumin). After 2 hours of incubation, bound or adsorbed proteins were separated, and sodium dodecyl sulfate-polyacrylamide gel electrophoresis was run at $150 \mathrm{~V}$ for 60 minutes and stained with Coomassie ${ }^{\circledR}$ G-250 stain. (B) Adsorbed protein bands were quantified by densitometry using AlphaEase Fc software. Data are reported as the mean of three repeats for each incubation (mean \pm standard error of the mean, $* P<0.05$, compared with PLGA curcumin nanoformulation). (C) Adsorption of curcumin nanoparticles on red blood cells using different concentrations of curcumin nanoformulations (10-40 $\mu \mathrm{M})$.

Notes: Data are reported as the mean of three repeats for each adsorption (mean \pm standard error of the mean deviation, $* P<0.05$, compared with free curcumin or PLGA curcumin nanoformulation).

Abbreviations: CD, $\beta$-cyclodextrin; CUR, curcumin; PLGA, polylactic-co-glycolic acid; HSA, human serum albumin. 
improve their in vivo circulation characteristics. ${ }^{59}$ Unlike particle-protein complexes, particles adhered on red blood cells or red blood cell mimic nanoparticles remain in the blood circulation unless there are large shear forces and cell-cell interactions. Therefore, we investigated the adhesion properties of curcumin particles in whole human blood. The adhesion process occurred after nanoparticles had interacted with plasma proteins in the blood. Adhesion of curcumin nanoparticles on red blood cells was determined by curcumin fluorescence using flow cytometry in channel 1 (488 excitation, blue laser, $530 \pm 15 \mathrm{~nm}$, fluorescein isothiocyanate/green fluorescent protein, Figure 3C). The order of adhered curcumin nanoparticles on red blood cells was found to be $\mathrm{PLGA}>$ nanogel $>\beta$-cyclodextrin $>$ cellulose $>$ dendrimer curcumin nanoformulations. The dendrimer exhibited very low adherence on red blood cells due to strong binding with plasma proteins, findings which are consistent with the above protein study.

From this study, our understanding is that both PLGA and nanogel curcumin nanoparticle interactions are minimal with both plasma proteins alone and in the presence of whole blood. Therefore, these formulations may be used for future in vivo and human clinical trials after detailed toxicological studies.

\section{Hemolysis}

Hemolysis is a type of acute toxicity assay used to evaluate the hemocompatibility of the nanomaterials and to detect hemolyzation of erythrocytes. ${ }^{60-63}$ To assess the in vivo utility of a nanoformulation as a carrier for curcumin, the hemolytic potential in human blood needs to be tested. ${ }^{64,65}$ Therefore, we evaluated a direct nanoparticle-erythrocyte membrane interaction in which the extent of disruption of the erythrocyte membrane was a direct measure of nanoparticle toxicity (Figure 4). The dark brown/red color (Figure 4A) signifies toxicity to red blood cells at those concentrations. The mechanism of red blood cell disruption depends entirely on the physical and chemical nature of the nanoformulations. Red blood cells treated with PLGA, $\beta$-cyclodextrin, cellulose, and nanogel curcumin nanoformulations showed no signs of hemolysis at any concentration tested (Figure 4B). This behavior is very similar to that of the negative control treatment (Figure 4B). The dendrimer curcumin nanoformulation did not show signs of hemolysis up to $100 \mu \mathrm{M}$, but after that, extreme dose-dependent hemolytic activity was observed (Figure 4B). Hemolysis is a rapid process and is likely due to binding with the negatively charged red blood cell membrane and its disturbance. This formulation demonstrated hemolysis equivalent to that of the positive control, suggesting that serious toxicity would occur in vivo. The extensive hemolysis of the dendrimer curcumin formulation results from the positively charged amino surface groups which are highly likely to destabilize the cell membrane and cause cell lysis. ${ }^{66}$ This type of lytic effect on red blood cells is extremely dangerous when administered in vivo, and
A

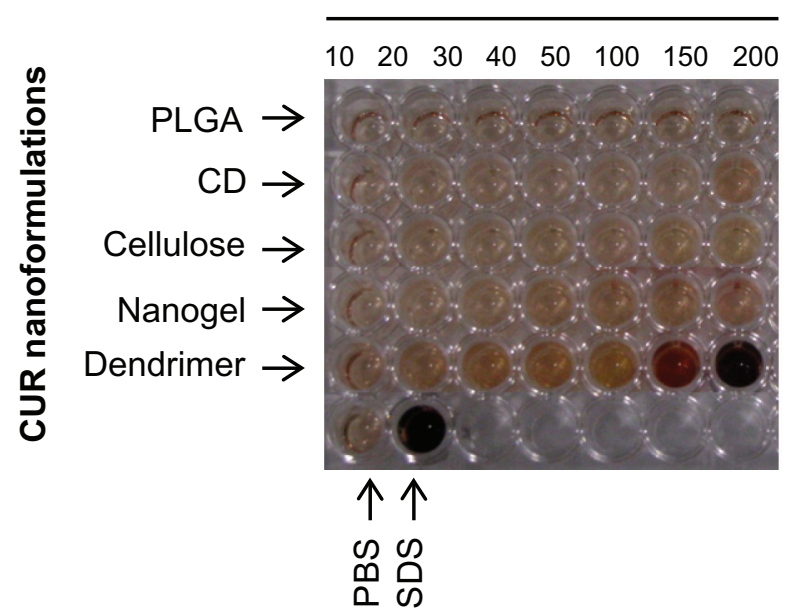

B

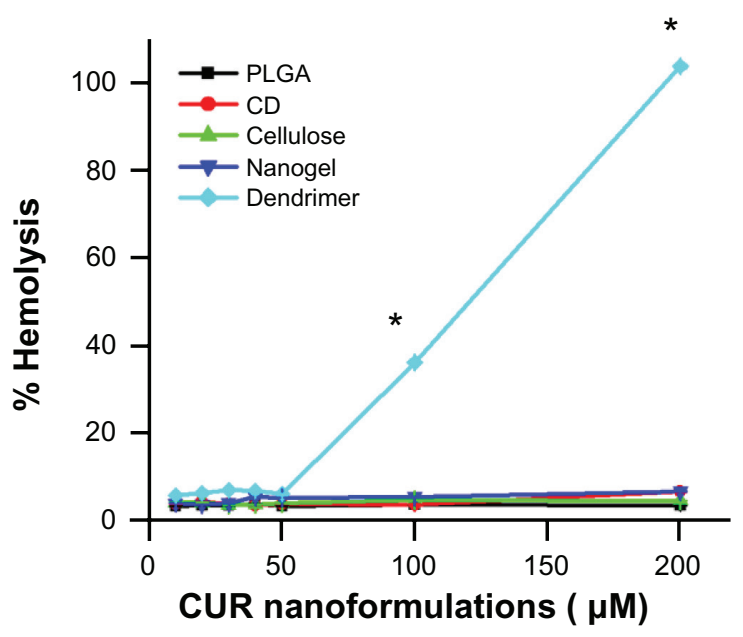

Figure 4 Hemolysis of curcumin nanoformulations incubated in red blood cells. (A) Optical image of supernatants from hemolysis study. Hemolysis was performed by incubating curcumin nanoformulations in red blood cells for two hours, centrifuging and collecting the supernatant for analysis. Phosphate-buffered solution and sodium dodecyl sulfate were considered as negative and positive controls in the experiment, respectively. (B) The extent of hemolysis was recorded by measuring optical density at $\lambda$ max $570 \mathrm{~nm}$ using an ultraviolet-visible spectrophotometer. The graph was normalized with respect to the optical density of sodium dodecyl sulfate (positive control, I00\% hemolysis).

Note: Data are presented as the mean of three repeats for each incubation (mean \pm standard error of the mean, $* P<0.05$, compared with the PLGA curcumin nanoformulation).

Abbreviations: CD, $\beta$-cyclodextrin; CUR, curcumin; PLGA, polylactic-co-glycolic acid; HSA, human serum albumin; PBS, phosphate-buffered solution; SDS, sodium dodecyl sulfate. 
therefore polyethylene glycol (PEG) conjugation or PEGylation of dendrimer formulations may be required to decrease this activity. ${ }^{67}$

Red blood cells exposed to curcumin nanoformulations as well as negative and positive hemolysis-inducing agents were analyzed for morphological variations providing visual evidence of hemolysis (Figure 5). Untreated red blood cells (negative control) have a normal biconcave shape with no visible surface abnormalities, whereas a positive hemolytic agent (sodium dodecyl sulfate) exposed to red blood cells clearly exhibits ghost cell morphology with numerous surface projections (Figure 5A). At low concentrations of all five curcumin nanoformulations $(50 \mu \mathrm{M})$, exposure did not show aberrant morphological variations (Figure 5B), implying that hemolytic activity was not present. There were no morphological alterations observed, even in red blood cells treated with $100 \mu \mathrm{M}$ of PLGA, $\beta$-cyclodextrin, cellulose, and nanogel curcumin nanoformulation, and no toxic effects were apparent (Figure 5C). However, a significant change in morphology and loss of biconcavity was observed when red blood cells were treated with the dendrimer curcumin nanoformulation, suggesting an increase in ghost cells and heavy hemolysis. This may be due to a higher rate of interaction or penetration of the dendrimer nanoparticles through the membranes of the red blood cells. ${ }^{68,69}$ This behavior is attributable to either direct interaction with enzymes or a change in ATPase activity by the dendrimer formulation. ${ }^{70}$ This activity may also depend on the type of dendrimer generated. ${ }^{71}$

Nanoparticle interactions with erythrocytes cause abnormal membrane proteins and lipids that lead to the destruction of erythrocyte integrity and hemolysis. To investigate why some curcumin formulations are toxic to erythrocytes at $100 \mu \mathrm{M}$, binding of nanoparticles and red blood cells was investigated using transmission electron microscopy. Nanoparticles can usually be internalized within cancer cells as well as by many other primary cells. However, in this study, all the curcumin nanoformulations failed to internalize in erythrocytes but instead attached to the membranes of the red blood cells (Figure 6). There were few PLGA, $\beta$-cyclodextrin, cellulose, or nanogel curcumin molecules on the membranes of erythrocytes (Figure 6, black arrows) compared with controls (Figure 6). A change in the morphology of the red blood cells from concave to spherical was observed, and secretion of some membrane proteins due to a higher rate of interaction with dendrimer curcumin nanoformulations (represented by squares) implies increased toxicity. This mainly occurs as a result of interaction between the dendrimer and the protein

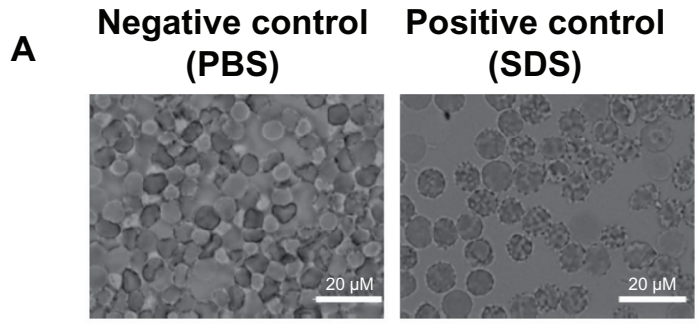

\section{CUR nanoformulations}

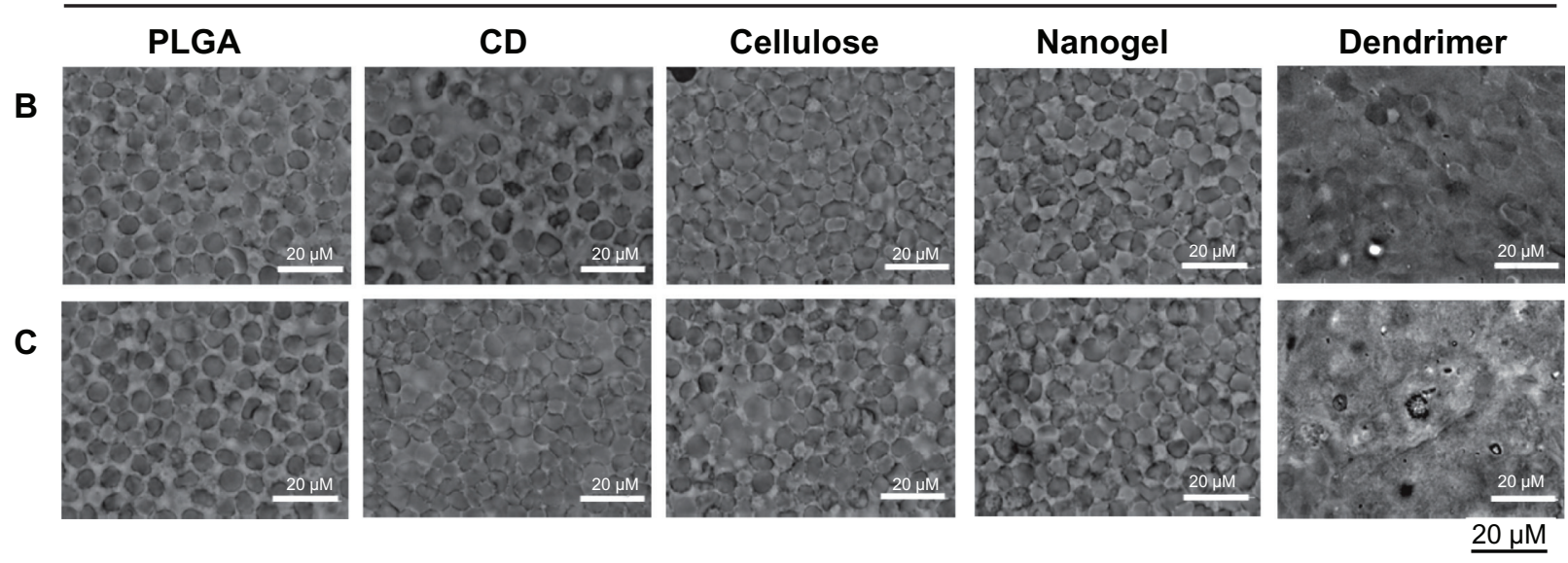

Figure 5 Morphological variation of red blood cells incubated with curcumin nanoformulations for 2 hours. Phase contrast images of red blood cells incubated with (A) controls (phosphate-buffered solution and sodium dodecyl sulfate), (B) curcumin nanoformulations ( $50 \mu \mathrm{M})$, and (C) curcumin nanoformulations (I00 $\mu \mathrm{M})$. Bar equals 20 microns. 

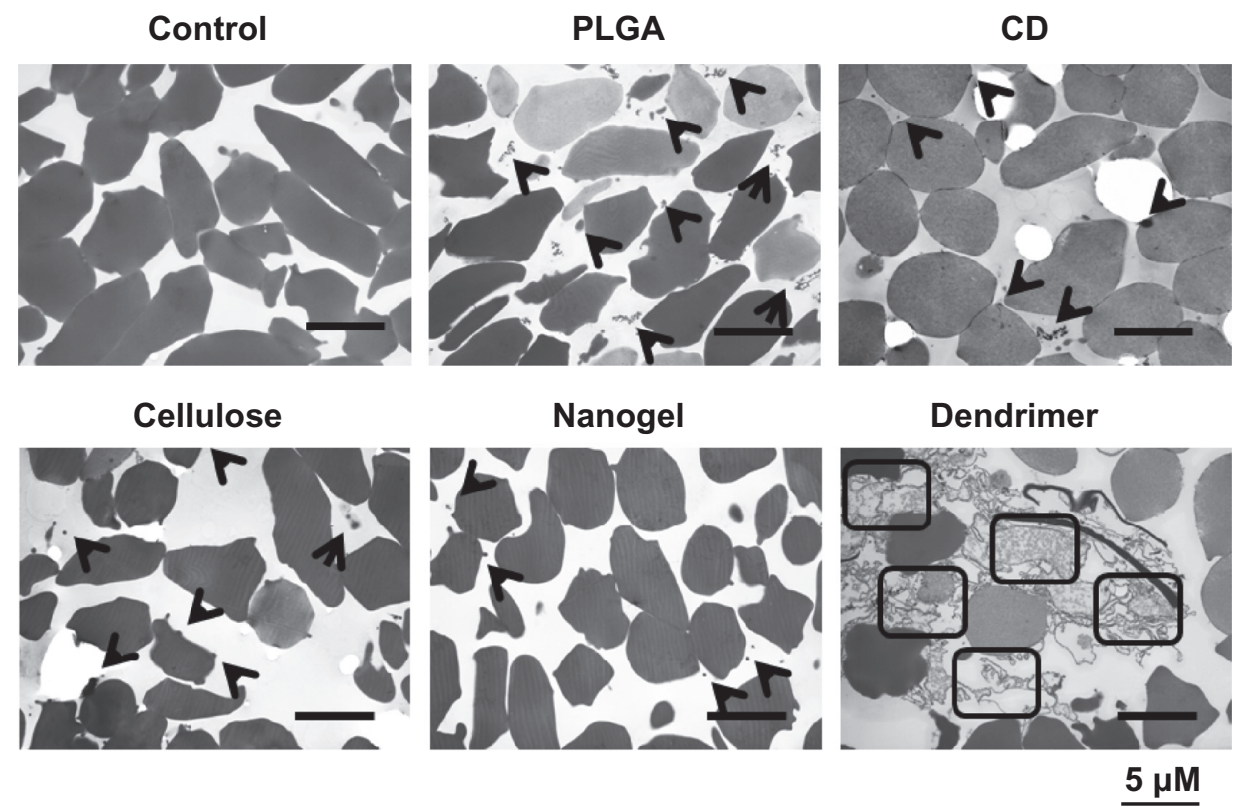

Figure 6 Attachment of curcumin nanoparticles to red blood cells. Transmission electron microscopic images of cross-sections of red blood cells after incubation with phosphate-buffered solution and curcumin nanoformulations (100 $\mu \mathrm{M})$. Bar equals 5 microns.

components of the plasma membrane, causing a change in the properties of the red blood cell membrane. ${ }^{71}$

Altogether, these results provide an interesting insight into the correlation between various curcumin nanoformulations and protein interactions that may impact in vivo efficacy. From the analysis of protein binding and hemolysis experiments, it can be concluded that all the curcumin nanoformulations behave differently than the dendrimer curcumin formulation. Our study clearly suggests that PLGA-based and nanogelbased curcumin formulations have lower protein binding, with no signs of hemolysis, demonstrating their suitability for therapeutic application. In vivo studies of PLGA and polyNIPAM nanogel curcumin formulations have shown improved bioavailability, and therefore are more effective systems for delivering curcumin into tumors. ${ }^{12,14,16,72,73}$ These data clearly support the overall conclusion of this study. Our future research efforts will include evaluation of the in vivo pharmacokinetics of these curcumin nanoformulations to clarify the underlying mechanisms for potential cancer therapeutics.

\section{Conclusion}

This work underlines the importance of selection of efficient curcumin nanoformulations for biomedical applications, in particular for cancer therapeutics. The selection process is based on assessing the interaction or binding of nanoformulations with common human blood proteins and erythrocytes. Overall, the study results indicate that PLGA and nanogel curcumin nanoformulations have lower interaction(s) with proteins and red blood cells and may predict better efficiency for in vivo therapeutic targets compared with other curcumin nanoformulations. Further, we believe that antibody-guided therapies using these curcumin formulations may be very useful for targeted tumor therapy and could replace conventional chemotherapeutics in the future.

\section{Acknowledgments}

The authors thank Cathy Christopherson and Jenna Hultgren for editorial assistance, Amber Kruse and Hillary Newby for maintenance of the cell cultures, and Robert Japs for his help with transmission electron microscopy characterization. The authors are also grateful to Susan Puumala and Ashley Miller, Methodology and Data Analysis Center, for statistical analyses. This work was partially supported by grants from Department of Defense (PC073887, PC073643), Governor's Cancer 2010, the National Institutes of Health Research Project Grant Program (RO1) (CA142736), and the Centers of Biomedical Research Excellence (P20 RR024219).

\section{Disclosure}

The authors report no conflicts of interest in this work.

\section{References}

1. ClinicalTrials.gov [homepage on the Internet]. Bethesda, MD: National Library of Medicine (US). Available from: http://clinicaltrials.gov/ct2/ home. Accessed Nov 2, 2011.

2. Hatcher H, Planalp R, Cho J, Torti FM, Torti SV. Curcumin: from ancient medicine to current clinical trials. Cell Mol Life Sci. 2008;65(11): $1631-1652$. 
3. Bar-Sela G, Epelbaum R, Schaffer M. Curcumin as an anti-cancer agent: review of the gap between basic and clinical applications. Curr Med Chem. 2010;17(3):190-197.

4. Maheshwari RK, Singh AK, Gaddipati J, Srimal RC. Multiple biological activities of curcumin: a short review. Life Sci. 2006;78(18): 2081-2087.

5. Abuzeid WM, Davis S, Tang AL, et al. Sensitization of head and neck cancer to cisplatin through the use of a novel curcumin analog. Arch Otolaryngol Head Neck Surg. 2011;137(5):499-507.

6. Bava SV, Puliappadamba VT, Deepti A, Nair A, Karunagaran D, Anto RJ. Sensitization of taxol-induced apoptosis by curcumin involves down-regulation of nuclear factor-kappaB and the serine/threonine kinase Akt and is independent of tubulin polymerization. J Biol Chem. 2005;280(8):6301-6308.

7. Chan MM, Fong D, Soprano KJ, Holmes WF, Heverling H. Inhibition of growth and sensitization to cisplatin-mediated killing of ovarian cancer cells by polyphenolic chemopreventive agents. J Cell Physiol. 2003;194(1):63-70.

8. Chatterjee SJ, Pandey S. Chemo-resistant melanoma sensitized by tamoxifen to low dose curcumin treatment through induction of apoptosis and autophagy. Cancer Biol Ther. 2011;11(2):216-228.

9. Deeb DD, Jiang H, Gao X, Divine G, Dulchavsky SA, Gautam SC. Chemosensitization of hormone-refractory prostate cancer cells by curcumin to TRAIL-induced apoptosis. J Exp Ther Oncol. 2005;5(2) 81-91.

10. Yallapu MM, Maher DM, Sundram V, Bell MC, Jaggi M, Chauhan SC. Curcumin induces chemo/radio-sensitization in ovarian cancer cells and curcumin nanoparticles inhibit ovarian cancer cell growth. J Ovarian Res. 2010;3:11.

11. Anand P, Thomas SG, Kunnumakkara AB, et al. Biological activities of curcumin and its analogues (Congeners) made by man and Mother Nature. Biochem Pharmacol. 2008;76(11):1590-1611.

12. Bansal SS, Goel M, Aqil F, Vadhanam MV, Gupta RC. Advanced drug delivery systems of curcumin for cancer chemoprevention. Cancer Prev Res (Phila). 2011;4(8):1158-1171.

13. Bisht S, Maitra A. Systemic delivery of curcumin: 21 st century solutions for an ancient conundrum. Curr Drug Discov Technol. 2009;6(3): 192-199.

14. Anand P, Kunnumakkara AB, Newman RA, Aggarwal BB. Bioavailability of curcumin: problems and promises. Mol Pharm 2007;4(6):807-818.

15. Kurien BT, Scofield RH. Increasing aqueous solubility of curcumin for improving bioavailability. Trends Pharmacol Sci. 2009;30(7): 334-335.

16. Anand P, Nair HB, Sung B, et al. Design of curcumin-loaded PLGA nanoparticles formulation with enhanced cellular uptake, and increased bioactivity in vitro and superior bioavailability in vivo. Biochem Pharmacol. 2010;79(3):330-338.

17. Antony B, Merina B, Iyer VS, Judy N, Lennertz K, Joyal S. A Pilot Cross-Over Study to Evaluate Human Oral Bioavailability of BCM-95CG (Biocurcumax), A Novel Bioenhanced Preparation of Curcumin. Indian J Pharm Sci. 2008;70(4):445-449.

18. Begum AN, Jones MR, Lim GP, et al. Curcumin structure-function, bioavailability, and efficacy in models of neuroinflammation and Alzheimer's disease. J Pharmacol Exp Ther. 2008;326(1): 196-208.

19. Shaikh J, Ankola DD, Beniwal V, Singh D, Kumar MN. Nanoparticle encapsulation improves oral bioavailability of curcumin by at least 9-fold when compared to curcumin administered with piperine as absorption enhancer. Eur J Pharm Sci. 2009;37(3-4):223-230.

20. Yan YD, Kim JA, Kwak MK, Yoo BK, Yong CS, Choi HG. Enhanced oral bioavailability of curcumin via a solid lipid-based self-emulsifying drug delivery system using a spray-drying technique. Biol Pharm Bull. 2011;34(8):1179-1186.

21. Yallapu MM, Gupta BK, Jaggi M, Chauhan SC. Fabrication of curcumin encapsulated PLGA nanoparticles for improved therapeutic effects in metastatic cancer cells. J Colloid Interface Sci. 2010;351(1):19-29.
22. Yallapu MM, Jaggi M, Chauhan SC. beta-Cyclodextrin-curcumin self-assembly enhances curcumin delivery in prostate cancer cells. Colloids Surf B Biointerfaces. 2010;79(1):113-125.

23. Gao Y, Li Z, Sun M, et al. Preparation and characterization of intravenously injectable curcumin nanosuspension. Drug Deliv. 2011;18(2): $131-142$.

24. Kakkar V, Singh S, Singla D, Kaur IP. Exploring solid lipid nanoparticles to enhance the oral bioavailability of curcumin. Mol Nutr Food Res. 2011;55(3):495-503.

25. Xie X, Tao Q, Zou Y, et al. PLGA Nanoparticles Improve the Oral Bioavailability of Curcumin in Rats: Characterizations and Mechanisms. J Agric Food Chem. 2011;59(17):9280-9289.

26. Yallapu MM, Dobberpuhl MR, Maher DM, Jaggi M, Chauhan SC. Design of Curcumin loaded Cellulose Nanoparticles for Prostate Cancer. Curr drug metab. 2011. [Epub ahead of print.]

27. Brigger I, Dubernet C, Couvreur P. Nanoparticles in cancer therapy and diagnosis. Adv Drug Deliv Rev. 2002;54(5):631-651.

28. Liang XJ, Chen C, Zhao Y, Jia L, Wang PC. Biopharmaceutics and therapeutic potential of engineered nanomaterials. Curr Drug Metab. 2008;9(8):697-709.

29. Zhang J, Wu L, Chan HK, Watanabe W. Formation, characterization, and fate of inhaled drug nanoparticles. Adv Drug Deliv Rev. 2010;63(6): $441-455$.

30. Bala I, Hariharan S, Kumar MN. PLGA nanoparticles in drug delivery: the state of the art. Crit Rev Ther Drug Carrier Syst. 2004;21(5): $387-422$.

31. Debbage P. Targeted drugs and nanomedicine: present and future. Curr Pharm Des. 2009;15(2):153-172.

32. Paudel KR, Rauniar GP, Bhattacharya SK, Das BP. Recent advancement in drug delivery system. Kathmandu Univ Med $J$ (KUMJ). 2008;6(2):262-267.

33. Cho K, Wang X, Nie S, Chen ZG, Shin DM. Therapeutic nanoparticles for drug delivery in cancer. Clin Cancer Res. 2008;14(5):1310-1316.

34. Thierry B. Drug nanocarriers and functional nanoparticles: applications in cancer therapy. Curr Drug Deliv. 2009;6(4):391-403.

35. Xie Y, Bagby TR, Cohen MS, Forrest ML. Drug delivery to the lymphatic system: importance in future cancer diagnosis and therapies. Expert Opin Drug Deliv. 2009;6(8):785-792.

36. Yallapu MM, Vasir JK, Jain TK, Vijayaraghavalu S, Labhasetwar V. Synthesis, Characterization and Antiproliferative Activity of Rapamycin-Loaded Poly(N-Isopropylacrylamide)-Based Nanogels in Vascular Smooth Muscle Cells. J Biomed Nanotechnol. 2008;4:16-24.

37. Panyam J, Labhasetwar V. Biodegradable nanoparticles for drug and gene delivery to cells and tissue. Adv Drug Deliv Rev. 2003;55(3): 329-347.

38. Vasir JK, Labhasetwar V. Biodegradable nanoparticles for cytosolic delivery of therapeutics. Adv Drug Deliv Rev. 2007;59(8):718-728.

39. Zhang J, Wu L, Chan HK, Watanabe W. Formation, characterization, and fate of inhaled drug nanoparticles. Adv Drug Deliv Rev. 2011;63(6): 441-455.

40. Emerich DF, Thanos CG. Targeted nanoparticle-based drug delivery and diagnosis. J Drug Target. 2007;15(3):163-183.

41. Shekunov B. Nanoparticle technology for drug delivery: from nanoparticles to cutting-edge delivery strategies - part II. IDrugs. 2005;8(5): 402-403.

42. Singh R, Lillard JW Jr. Nanoparticle-based targeted drug delivery. Exp Mol Pathol. 2009;86(3):215-223.

43. Mukerjee A, Vishwanatha JK. Formulation, characterization and evaluation of curcumin-loaded PLGA nanospheres for cancer therapy. Anticancer Res. 2009;29(10):3867-3875.

44. Prajakta D, Ratnesh J, Chandan K, et al. Curcumin loaded pH-sensitive nanoparticles for the treatment of colon cancer. J Biomed Nanotechnol. 2009;5(5):445-455.

45. Sou K, Oyajobi B, Goins B, Phillips WT, Tsuchida E. Characterization and cytotoxicity of self-organized assemblies of curcumin and amphiphatic poly(ethylene glycol). J Biomed Nanotechnol. 2009;5(2) 202-208. 
46. Lynch I, Cedervall T, Lundqvist M, Cabaleiro-Lago C, Linse S, Dawson KA. The nanoparticle-protein complex as a biological entity; a complex fluids and surface science challenge for the 21 st century. Adv Colloid Interface Sci. 2007;134-135:167-174.

47. Ehrenberg MS, Friedman AE, Finkelstein JN, Oberdorster G, McGrath JL. The influence of protein adsorption on nanoparticle association with cultured endothelial cells. Biomaterials. 2009;30(4):603-610.

48. Horie M, Nishio K, Fujita K, et al. Protein adsorption of ultrafine metal oxide and its influence on cytotoxicity toward cultured cells. Chem Res Toxicol. 2009;22(3):543-553.

49. Kastantin M, Missirlis D, Black M, Ananthanarayanan B, Peters D, Tirrell M. Thermodynamic and kinetic stability of DSPE-PEG(2000) micelles in the presence of bovine serum albumin. J Phys Chem B. 2010;114(39):12632-12640.

50. Lacerda SH, Park JJ, Meuse C, et al. Interaction of gold nanoparticles with common human blood proteins. ACS Nano. 2010;4(1):365-379.

51. Monopoli MP, Walczyk D, Campbell A, et al. Physical-chemical aspects of protein corona: relevance to in vitro and in vivo biological impacts of nanoparticles. J Am Chem Soc. 2010;133(8):2525-2534.

52. Yallapu MM, Foy SP, Jain TK, Labhasetwar V. PEG-functionalized magnetic nanoparticles for drug delivery and magnetic resonance imaging applications. Pharm Res. 2010;27(11):2283-2295.

53. Bihari P, Vippola M, Schultes S, et al. Optimized dispersion of nanoparticles for biological in vitro and in vivo studies. Part Fibre Toxicol. 2008;5:14.

54. Zhang X, Yin L, Tang M, Pu Y. Optimized method for preparation of TiO2 nanoparticles dispersion for biological study. J Nanosci Nanotechnol. 2010;10(8):5213-5219.

55. Ruso JM, Taboada P, Varela LM, Attwood D, Mosquera V. Adsorption of an amphiphilic penicillin onto human serum albumin: characterisation of the complex. Biophys Chem. 2001;92(1-2):141-153.

56. Almeida JP, Chen AL, Foster A, Drezek R. In vivo biodistribution of nanoparticles. Nanomedicine (Lond). 2011;6(5):815-835.

57. Jokerst JV, Lobovkina T, Zare RN, Gambhir SS. Nanoparticle PEGylation for imaging and therapy. Nanomedicine (Lond). 2011;6(4):715-728.

58. Semete B, Booysen L, Lemmer Y, et al. In vivo evaluation of the biodistribution and safety of PLGA nanoparticles as drug delivery systems. Nanomedicine. 2010;6(5):662-671.

59. Chambers E, Mitragotri S. Long circulating nanoparticles via adhesion on red blood cells: mechanism and extended circulation. Exp Biol Med (Maywood). 2007;232(7):958-966.

60. Ciochina AD, Bredetean O, Dimitriu DC, Iacob G. Considerations on in vitro and in vivo magnetic nanoparticles hemocompatibility testing. Rev Med Chir Soc Med Nat Iasi. 2009;113(1):279-285.
61. Koziara JM, Oh JJ, Akers WS, Ferraris SP, Mumper RJ. Blood compatibility of cetyl alcohol/polysorbate-based nanoparticles. Pharm Res. 2005;22(11):1821-1828.

62. Mayer A, Vadon M, Rinner B, Novak A, Wintersteiger R, Frohlich E. The role of nanoparticle size in hemocompatibility. Toxicology. 2009; 258(2-3):139-147.

63. Shelma R, Sharma CP. Development of lauroyl sulfated chitosan for enhancing hemocompatibility of chitosan. Colloids Surf B Biointerfaces. 2011;84(2):561-570.

64. Fischer HC, Chan WC. Nanotoxicity: the growing need for in vivo study. Curr Opin Biotechnol. 2007;18(6):565-571.

65. Grainger DW. Nanotoxicity assessment: all small talk? Adv Drug Deliv Rev. 2009;61(6):419-421

66. Fischer D, Li Y, Ahlemeyer B, Krieglstein J, Kissel T. In vitro cytotoxicity testing of polycations: influence of polymer structure on cell viability and hemolysis. Biomaterials. 2003;24(7):1121-1131.

67. Wang W, Xiong W, Zhu Y, Xu H, Yang X. Protective effect of PEGylation against poly(amidoamine) dendrimer-induced hemolysis of human red blood cells. J Biomed Mater Res B Appl Biomater. 2010; 93(1):59-64.

68. Sutherland E, Dixon BS, Leffert HL, Skally H, Zaccaro L, Simon FR. Biochemical localization of hepatic surface-membrane $\mathrm{Na}+\mathrm{K}+-\mathrm{ATPase}$ activity depends on membrane lipid fluidity. Proc Natl Acad Sci USA. 1988;85(22):8673-8677.

69. Chen $\mathrm{CH}$, Zuklie BM, Roth LG. Elucidation of biphasic alterations on acetylcholinesterase (AChE) activity and membrane fluidity in the structure-functional effects of tetracaine on AChE-associated membrane vesicles. Arch Biochem Biophys. 1998;351(1):135-140.

70. Klajnert B, Sadowska M, Bryszewska M. The effect of polyamidoamine dendrimers on human erythrocyte membrane acetylcholinesterase activity. Bioelectrochemistry. 2004;65(1):23-26.

71. Ciolkowski M, Rozanek M, Szewczyk M, Klajnert B, Bryszewska M. The influence of PAMAM-OH dendrimers on the activity of human erythrocytes ATPases. Biochim Biophys Acta. 2011;1808(11):2714-2723.

72. Bisht S, Mizuma M, Feldmann G, et al. Systemic administration of polymeric nanoparticle-encapsulated curcumin (NanoCurc) blocks tumor growth and metastases in preclinical models of pancreatic cancer. Mol Cancer Ther. 2010;9(8):2255-2264.

73. Lim KJ, Bisht S, Bar EE, Maitra A, Eberhart CG. A polymeric nanoparticle formulation of curcumin inhibits growth, clonogenicity and stem-like fraction in malignant brain tumors. Cancer Biol Ther. 2011; 11(5):464-473.
International Journal of Nanomedicine

\section{Publish your work in this journal}

The International Journal of Nanomedicine is an international, peerreviewed journal focusing on the application of nanotechnology in diagnostics, therapeutics, and drug delivery systems throughout the biomedical field. This journal is indexed on PubMed Central, MedLine, CAS, SciSearch $\AA$, Current Contents ${ }^{\circledR} /$ Clinical Medicine,

\section{Dovepress}

Journal Citation Reports/Science Edition, EMBase, Scopus and the Elsevier Bibliographic databases. The manuscript management system is completely online and includes a very quick and fair peer-review system, which is all easy to use. Visit http://www.dovepress.com/ testimonials.php to read real quotes from published authors. 